\title{
Epidemiology of hypertension and its relationship with type 2 diabetes and obesity in eastern Morocco
}

\author{
Abderrahim Ziyyat ${ }^{*}$, Noureddine Ramdani ${ }^{1}$, Nour El Houda Bouanani ${ }^{1}$, Jean Vanderpas ${ }^{2}$, Benyounès Hassani ${ }^{3}$, \\ Abdeslam Boutayeb ${ }^{4}$, Mohammed Aziz ${ }^{1}$, Hassane Mekhfi ${ }^{1}$, Mohammed Bnouham ${ }^{1}$ and Abdelkhaleq Legssyer ${ }^{1}$
}

\begin{abstract}
The major objectives of this work are to estimate the hypertension (HT) frequency in the east of Morocco and to study the relationship between HT, type 2 diabetes and obesity. Our sample is composed of 1628 adults aged 40 years and older, recruited voluntarily by using the convenience sampling method through 26 screening campaigns in urban and rural areas of the east of Morocco. We enumerated 516 hypertensive people (31.7\%), without significant difference between women (32.5\%) and men (30.2\%). The known hypertensive people represent $10.1 \%$ of the whole sample. The frequency of $H T$, increases with age and it is more marked in rural (39.9\%) than in urban areas (29\%) $(p<0.001)$. It is significantly very high in diabetic subjects $(69.9 \%)$ than among the non-diabetic ones (27.4\%) $(p<0.001)$. The odd ratio (OR) of the diabetics to HT is 6.16 (IC95\% [4.33-8.74]). Among the obese persons, $H$ T is present at (40.8\%) vs. (30.2\%) among the subjects of normal weight $(p<0.05)$. The OR of the obese to HT is 1.6 (IC95\% [1.26 - 2.04]). In conclusion, our results show a high frequency of HT in the east of Morocco; it affects nearly one third of the adult population aged 40 years and older. The relations between type 2 diabetes and obesity have also been identified and estimated.
\end{abstract}

Keywords: Hypertension; Type 2 diabetes; Obesity; Abdominal obesity; Eastern Morocco

\section{Introduction}

Hypertension (HT) is a silent disease that affects the cardiovascular system and settles down without pain and symptoms at the beginning; therefore, it is bad or late diagnosed (WHO 2012; Nejjari et al. 2013). HT affects various organs and engenders grave affections; such as vascular cerebral accident and heart disorder (Nejjari et al. 2013). When the hypertensive patients are bad treated or untreated, the disease reduces the flexibility of arteries, what favors the apparition of the cardiac insufficiency, angina pectoris, atherosclerosis, stroke cerebral, microvascular diseases of retina and glomerulus (UKPDS 1998; Cohuet and Struijker-Boudier 2006). The management of the HT becomes more difficult when it is accompanied by diabetes and obesity (Garcia et al. 2008). The

\footnotetext{
* Correspondence: ziyyat@yahoo.fr

'Laboratoire de Physiologie et Ethnopharmacologie, Département de Biologie - Faculté des Sciences, Université Mohamed Premier, B.P. 717, Boulevard Mohamed VI, Oujda 60000, Maroc

Full list of author information is available at the end of the article
}

relations between these three affections are strong and well demonstrated (UKPDS 1998; Grossman and Messerli 1996; Hayashi et al. 2004). Multiple factors such as age, sex, stress, residence, physical inactivity and dietary habits are associated with this vascular disease (Joffres et al. 1997; Tazi et al. 2003; Karppanen and Mervaala 2006; Rosenthal and Alter 2012).

Regarding the epidemiology of HT, its prevalence is very worrying; the recent report of the WHO (WHO 2012) shows that one of three adults in the world is affected by HT, more than 2 billion people, most of whom are not diagnosed (Nejjari et al. 2013). In Africa, its prevalence exceeds $40 \%$ among adults in many countries often undiagnosed (Nejjari et al. 2013). At The Grand Maghreb, an international epidemiological, multicentric and transversal study conducted among patients who consult doctors in Algeria, Tunisia and Morocco, has

\section{勿}

(C) 2014 Ziyyat et al.; licensee Springer. This is an Open Access article distributed under the terms of the Creative Commons Attribution License (http://creativecommons.org/licenses/by/4.0), which permits unrestricted use, distribution, and reproduction in any medium, provided the original work is properly credited. 
reported an overall prevalence around 45.4\% (Nejjari et al. 2013). In 2000, the ministry of health in Morocco published a prevalence of HT around 33.6\% (30.2\% for men and $37.0 \%$ for women) among a population aged more than twenty years (Tazi et al. 2003). To our knowledge, there are no field studies conducted in eastern Morocco of the prevalence of this disease except the work published by our team on the phytotherapy of HT and diabetes in 1997 (Ziyyat et al. 1997).

This study is considered as the follow-up and the continuity of a previous and original work carried out in the east of Morocco, concerning the screening of obesity, HT and mainly type 2 diabetes. The first results of the diabetes and obesity have been published in 2012 (Ramdani et al. 2012).

The main objectives of this study are to estimate the HT frequency among a population over the age of 40 years, living in the rural and urban regions of the east of Morocco, and to study the existing relations between this vascular pathology, type 2 diabetes and obesity taking into account the other intervening factors.

\section{Methods \\ Sample}

It is necessary to note that the subjects constituting this sample are the same individuals of the aforementioned work, which aimed mainly to estimate the frequency of type 2 diabetes. For that reason, two criteria have been set for the individuals to take part in this study: a minimum age of 40 years old and being fasting. The subjects had been previously informed of this study and they had voluntarily agreed to participate. They were recruited during the screening and prevention campaigns organized in collaboration with the health organizations and associations of civil society. They came mainly to test their blood sugar levels, their blood pressure and to identify their weight profile (Ramdani et al. 2012).

For practical reasons and especially sociocultural ones, it was difficult to take anthropometric and glycaemic measures for women in their homes while men were not there. To overcome this problem which prevented us from ensuring a random sampling, we opted for the convenience sampling method. This method has been detailed and discussed in the first article (Ramdani et al. 2012).

\section{Survey and questionnaire}

The survey was conducted by a group of researchers trained in our laboratory. The realization of this work passes into four steps:

1. Demographic data;

2. Anthropometric data;

3. Risk factors data;

4. Measurement of arterial pression and glycemia.
Diagnosis criteria of $\mathrm{HT}$, diabetes and obesity

$\mathrm{HT}$ is considered if the systolic blood pressure (SBP) is greater than $140 \mathrm{mmHg}$ or if the diastolic blood pressure (DBP) is higher than $90 \mathrm{mmHg}$ (Mancia et al. 2007).

Diabetes (DM) is reported when the fasting blood glucose exceeds $1.26 \mathrm{~g} / \mathrm{l}$ (Alberti et al. 1998).

Obesity is defined by a Body Mass Index BMI $\geq 30$ $\mathrm{kg} / \mathrm{m}^{2}$ (WHO 2003).

For abdominal obesity, it is considered in two ways (WHO 2003):

"Waist measurement (WC) $\geq 102 \mathrm{~cm}$ among men and $\geq 88 \mathrm{~cm}$ among women.

"Waist-to-hip ratio $(\mathrm{W} / \mathrm{H})$ above 0.8 for women and 1.0 for men.

\section{Statistics}

Data analysis was carried out in the unit of Epidemiology at Brugmann University hospital (Brussels, Belgium) using SPSS software version 17.0. The continuous variables are presented as the means $\pm \mathrm{SD}$. The comparison of averages was performed with the test $\mathrm{Z}$. The chi-square test was used to look for the dependency between the categorical variables. The univariate analysis has served in the study of binary relations between two variables. The odd ratio (OR) was used to measure the force of association between them. An $(\mathrm{OR}>1)$ was considered as a risk factor when $\mathrm{p}<0,05$. To elucidate the relationship between several variables at the same time we made a multivariate analysis by logistic regression; the variables selected were those that had statically significant effects $(\mathrm{p}<0.05)$.

The sample size was calculated by the formula: $n=$ $p(1-p) X Z^{2} / i^{2}$; where ' $\mathrm{n}$ ' is the expected size of the sample; ' $p$ ' is the estimated proportion of diabetes among the Moroccan population (6.6\%) according to ministry of Health (Tazi et al. 2003); ' $Z$ ' is the critical value (percentile) for the standard normal distribution (1.96 for a 95\% confidence interval C195); and ' $i$ ' is the acceptable margin of error. For more security, we preferred to work with an interval instead of a fixed value. In our case " $\mathrm{i}$ " is between 1 and $2 \%$. The calculations have led to numbers contained between 600 and 2300 subjects. We integrated initially 2027 detected people, after applying the inclusion and exclusion criteria mentioned above, the final sample took a final size of 1628 cases,

\section{Ethics}

See the first article (Ramdani et al. 2012).

Limits

See the first article (Ramdani et al. 2012). 


\section{Results}

Our sample consists of 1628 subjects, the majority of them are women $63.4 \%$ compared to men $36.6 \%$ ( $<<0.001)$. The subjects in urban regions constitute a number of (1224) individuals; the rest (404) live in rural regions $(\mathrm{p}<0.001)$. The frequencies of HT, diabetes and obesity are presented in Figure 1 . We remind that our database contains the measures of blood pressure and blood glucose of 1628 screened subjects; also, we signal that 80 data concerning the anthropometric measures are missing.

\section{Arterial hypertension in the total sample:}

The means and the values [min and max] of the SBP and the DBP are respectively $130.2 \pm 20.3 \mathrm{~mm} \mathrm{Hg}$ [80-230] and $80.1 \pm 10.2 \mathrm{~mm} \mathrm{Hg}$ [50-160]). "120" and "80" mm Hg are the values modes of SBP and DBP respectively. $65.4 \%$ of 1628 screened subjects were with a normal blood pressure, $2.9 \%$ were hypotensive, and $31.7 \%$ were hypertensive without significant difference between women $32.5 \%$ and men $30.2 \%$. It should be noted that only 164 people (31.8\%) from 516 hypertensive are aware of their disease (HT). Concerning the age factor the hypertensive subjects have the highest mean of age (58.2 years old) compared with normotensive (52.3 years old) and hypotensive people (50.4 years old). Regarding the residence factor, the frequency of HT in the rural regions was higher (39.9\%) than in urban ones $(29 \%)(\mathrm{p}<0.001)$.

$26 \%$ of all screened subjects didn't know if HT existed among their families. $35 \%$ of the hypertensive patients confirmed the presence of HT in at least one member of their families (ascendants or collaterals) versus 25.9\% among normotensive subjects; the difference is significant $(\mathrm{p}<0.05)$.

\section{$\mathrm{HT}$ and diabetes}

We should remind that in this investigation, the frequency of type 2 diabetes in the east of Morocco has been 10,2\% without significant difference between women (10.7\%) and men (9.3\%) (Ramdani et al. 2012).

The average SBP is high in diabetics $(140.3 \pm 20.6 \mathrm{~mm}$ $\mathrm{Hg})$ compared with non diabetics $(130.1 \pm 20.2 \mathrm{~mm} \mathrm{Hg})$ $(\mathrm{p}<0.05)$. For the DBP we have not noted any significant difference $(80.1 \pm 10.2$ vs. $80.3 \pm 10.3 \mathrm{~mm} \mathrm{Hg})$.

As for the relationship between HT and diabetes, we have found that $22.5 \%$ of all 516 hypertensive patients were diabetics against $4.5 \%$ among the non hypertensive subjects $(\mathrm{p}<0.001)$. On the other side, HT is significantly frequent among diabetics $69.9 \%$ compared with non diabetic subjects $27.4 \%(\mathrm{p}<0.001)$. The OR of the diabetics for HT is 6.16 (CI 95\% [4.33 to 8.74]).

When considering the sex factor, we have found that among the 112 diabetic women, $73.2 \%$ were hypertensive vs $27.7 \%$ among non diabetic counterparts. Among the male sex, the situation is similar: $63 \%$ of all 54 diabetic men are hypertensive compared to $26.8 \%$ of those who are non diabetics (Table 1 ). The Khi- 2 test has confirmed this association between HT and diabetes of the two sexes ( $\mathrm{p}<0.001)$; thus the OR for HT is of 7.1 (CI95\% [4.59 to 11.12]) and 4.63 (CI95\% [2.58 to 8.31]) among diabetic women and men respectively.

Finally, integrating the residence parameter, we have found that $25.1 \%$ and $16.8 \%$ of urban and rural hypertensive, respectively, are diabetics; the difference is very significant compared to the non hypertensive subjects. The OR for HT in diabetic patients living in the rural is 9.59 (CI95\% [3.6 - 25.48], it is higher than that of patients living in the city: 6.13 (CI95\% [4.17 - 8.99]).

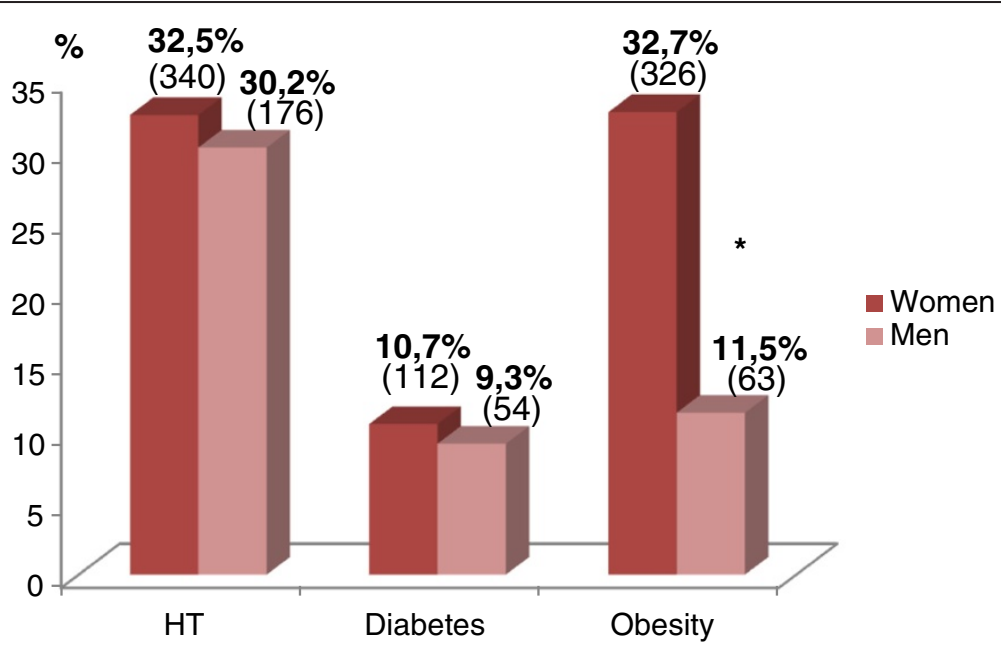

Figure 1 Proportions and corresponding numbers (in parentheses) of HT, diabetes and obesity among women and men. (Reminder: 80 data of $\mathrm{BMl}$ are missing). ${ }^{*} \mathrm{p}(\mathrm{F} / \mathrm{H})<0,001$. 
Table 1 Proportions and corresponding numbers (in parentheses) of women and men with HT in diabetics and non diabetics

\begin{tabular}{|c|c|c|c|c|c|c|c|}
\hline & \multicolumn{2}{|c|}{ Total of hypertensive (516) } & \multicolumn{2}{|c|}{ Women hypertensive (340) } & \multicolumn{3}{|c|}{ Men hypertensive (176) } \\
\hline & Number & $\%$ & Number & $\%$ & Number & $\%$ & $P(W / M)$ \\
\hline Diabetics & (116) & $69,9 \%$ & $(82)$ & $73,2 \%$ & (34) & $63 \%$ & $<0,05$ \\
\hline Non diabetics & $(400)$ & $27,4 \%$ & (258) & $27,7 \%$ & $(142)$ & $26,8 \%$ & NS \\
\hline$p$ (diab/Non diab) & $<0,001$ & & $<0,001$ & & $<0,001$ & & - \\
\hline
\end{tabular}

\section{Hypertension and obesity}

In this survey, the frequency of obesity in the east of Morocco was $25.1 \%$ with significant differences between women $(32.7 \%)$ and men (11.5\%) and between the urban regions $(27.7 \%)$ and the rural ones (17.7\%) (Ramdani et al. 2012).

In general, the average SBP is high among the obese $(138.0 \pm 20.4 \mathrm{~mm} \mathrm{Hg})$ compared with non obese (130.0 \pm $20.3 \mathrm{~mm} \mathrm{Hg})(\mathrm{p}<0.05)$. For the DBP, we have not noted any significant difference $(80.4 \pm 10.3$ vs. $80.2 \pm$ $10.2 \mathrm{~mm} \mathrm{Hg})$.

$40.6 \%$ of 389 obese are hypertensive vs $30.2 \%$ among 1159 non obese $(\mathrm{p}<0.05)$. The OR for HT in obese subjects is 1.6 (CI95\% [1.26-2.04]).

When we integrate the sex factor we find that $38.4 \%$ among the 326 obese women and 51.6\% among the 63 obese men are hypertensive vs $31.4 \%$ and $28.6 \%$ among non obese women and men respectively; the differences are significant (Table 2). The chi-square test confirmed the association between these two disorders in both sexes. Thus, the OR of obese women and men for HT is of 1.4 (CI95\% [1.0-1.8]) and 2.7 (CI95\% [1.6-4.6]) respectively.

When considering the residence factor, we don't find any significant differences between the frequency of HT among obese subjects in urban regions (38, 6\%) and those in rural ones (45.6\%), and between the non obese in urban regions (34.2\%) and those in rural ones (38.5\%).

\section{Discussion}

\section{Frequency of HT}

In our study, the frequency of hypertension (31.7\%) was similar to that found in a national survey by the Ministry of Health (33.6\%) (Tazi et al. 2003) and that found in the region of Tlemcen (32.7\%) (Boukli Hacène and Meguenni 2007). However, we worked on a population aged 40 and over, while in the national survey, age was set at 20 years and older. We believe that our result is more realistic given that hypertension is rare in the age group 20-40 years. In addition, our study was conducted in a particular region that is a border area with Algeria to the east and with the enclave of Melilla in the north. Therefore, the black market is widespread and the area receives various products including food products from Europe, Asia, Africa, etc... This can have a direct influence on eating habits and consequently on the health of the citizens of this region.

Moreover, the results we found are not quite the same as the national survey; for example, in our study, the frequency of hypertension shows no significant difference between men (30.2\%) and women (32.5\%) while in the national survey, it is significantly higher among women (37\% vs 30.2) (see other intervening factors). Moreover, in our study the frequency of obesity is much higher among women $(32.7 \%)$ compared to that found in the national survey (22\%).

\section{Other intervening factors}

Sex: The frequency of HT among women (32.5\%) is slightly higher than it is among men (30.2\%), but without significant difference. In the national survey of the health ministry, women are more affected by HT (37\%) than men (30.2\%) (Tazi et al. 2003). The impact of sex on HT is highly controversial. Indeed, the work of Barrios and colleagues showed that women, for unknown reasons, are at greater risk of hypertension (Barrios et al. 2008). In a survey conducted in France in 2007, it is quite the opposite: the frequency of HT was higher in men $(34.1 \%)$ than in women $(27.8 \%)$ (Godet-Thobie et al. 2008).

Residence: Regarding this parameter, our results do not differ from the general trend of HT in urban and rural regions in Morocco. Thus, its frequency is significantly

Table 2 Proportions and corresponding numbers for women and men with HT in obese and non obese

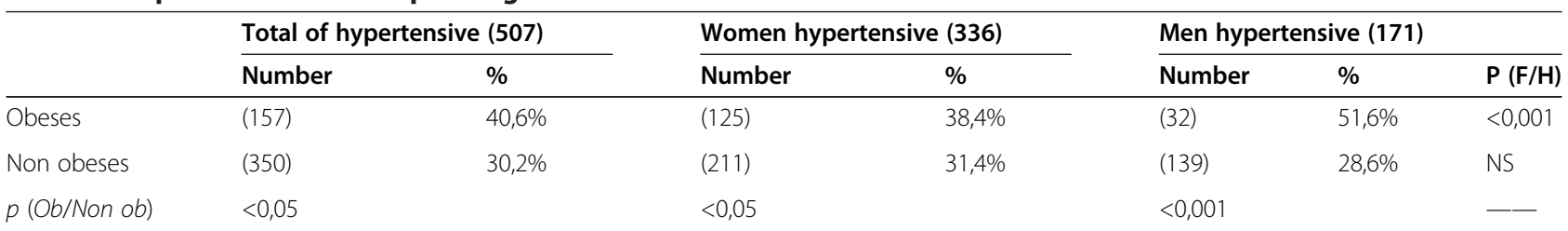

(Reminder: 80 data of BMI are missing). 
higher in rural regions (39.9\%) compared with urban regions (29.04\%). In Morocco, the official prevalence of HT in the rural is $43.3 \%$ vs $32.6 \%$ in the city (Tazi et al. 2003). Tazi explained this difference by the effect of stress in the rural life, especially in times of drought which sometimes lasts for successive years. The relationship between stress and HT is well documented (Rosenthal and Alter 2012).

In our situation, we can also talk about the impact of diet with emphasis on the too salty nature of many traditional dishes very well known in the countryside of eastern Morocco. We cite for examples some dishes as they are named in this region: Guéddid (pieces of meat cut into long, salted and dried in the sun), Smen (traditional salted butter) and Lakhliae (meat cooked in fat and salt). Indeed, these dishes are very rich in salt used for food preservation, since refrigerators are not yet widely available in rural areas and lack of electricity in some rural areas. The relationship between hypertension and sodiumrich diet is confirmed (Karppanen and Mervaala 2006; Vargas Alarcón 2006).

Finally, we can also mention the factor of consanguinity (Vargas Alarcón 2006), since rural areas and villages in eastern Morocco especially the southern part, are known by marriage within the tribe and cousins of the same family. The analysis of this factor in our database shows that $48.8 \%$ of hypertensive patients in rural areas have reported the presence of hypertension in the family against only $33 \%$ in urban areas; the difference is significant. In the literature, consanguinity and genetic factors are important parameters both of which contribute to the development of hypertension (Vargas Alarcón 2006).

Age: The frequency of HT in our sample increases with age in both sexes. Thus, we move from $23.4 \%$ and $9.7 \%$ in the first group [ $40-49$ years old] to $52.6 \%$ and $51.5 \%$ for subjects aged over 70 years among women and men respectively. The increase of the frequency of HT along with age was known (Renzaho et al. 2014), and was also mentioned in the official report of the Ministry of Health on HT in Morocco (Tazi et al. 2003). This association is logical, because the human body accumulates, over time, the risk factors of HT.

\section{Relationship between $\mathrm{HT}$ and diabetes}

$22.5 \%$ of all 516 hypertensive patients are diabetics, vs only $4.5 \%$ among normotensive subjects. On the other side, $69 \%$ of the diabetics are hypertensive, vs $27.4 \%$ among non diabetics. The differences are highly significant in both cases. The risk of diabetics for HT is very high; OR $=6.16$ (CI95\% [4,33-8,74]). These results confirm the findings in the studies on the high incidences of HT in diabetic patients and vice versa, either in Morocco (Berraho et al. 2009), or in the world (UKPDS 1998; WHO 1985; Sowers 2003). The frequency of diabetes coexisting with hypertension is increasing in most developing and industrialized countries; for example, in the United States, the hypertension has been involved in $4.4 \%$ of deaths of diabetics, and diabetes was implicated in $10 \%$ of deaths of hypertensive persons. (The National High Blood Pressure Education Program Working Group 1994).

Regarding sex factor, we have found that the OR for HT is 7.1 (95\% CI [4.59-11.12]) among diabetic women and 4.63 (CI95\% [2.58-8.31]) among diabetic men. The relationship between type 2 diabetes, HT and sex factor has been studied and debated for a long time (WHO 1985; Stamler et al. 1993). Some studies indicate that diabetic women are more exposed to $\mathrm{HT}$ as it is the case in this work (Howards et al. 2006; Fidiarivony et al. 2010), it may be due to obesity factor, since we have found that they are more affected by excess weight. The search early of hypertension should be a habit of follow up of diabetics.

\section{Relation HT and obesity}

The OR of obese subjects for HT is 1.6 (CI95\% [1.262.04]). These results are consistent with several studies showing a high incidence of HT in obese persons (Jordan et al. 2007; Hall et al. 2001; Maniecka-Bryla et al. 2011). Physiologically, activation of the sympathetic nervous system, renal retention and activation of the renin-angiotensin system sodium seem to have a common point in the different diagrams proposed to explain this association (Vargas Alarcón 2006; Hall et al. 2001; Da Silva et al. 2009; Jansen et al. 2010).

Regarding the sex factor we find that obese men are more exposed to HT than obese women. To explain this, we have introduced the parameter of abdominal obesity, because several studies suggest its importance as a major risk factor for $\mathrm{HT}$ and cardiovascular diseases (Maniecka-Bryla et al. 2011; Gus et al. 2004; Janssen et al. 2004; Chuang et al. 2006). Indeed, the results of the comparison have showed that obese men have an average of waist circumference $(113.8 \pm 9.2 \mathrm{~cm})$ and the ratio 'W/H' $(1.22 \pm 0.07)$, they are significantly higher than those found in obese women $(104.3 \pm 12.4 \mathrm{~cm}$ and $0.91 \pm 0.08)$.

The disturbance in plasma concentrations of adipokines (especially the reduction in adiponectine), an enzyme secreted by the adipose tissue will play the role of hormonal signalling of inflammatory processes and contribute to the occurrence of insulin resistance and the dysfunction of the endothelium by a deficit of production of Nitric oxide 'NO' (Aprahamian and Sam 2011). This hypo adiponectinemy is considered as a risk factor for coronary artery disease and HT (Garcia et al. 2008; Aprahamian and Sam 2011). 


\section{Relation between $\mathrm{HT}$, diabetes and obesity}

To elucidate this relation in our sample, we conducted a multivariate analysis by logistic regression. HT is chosen as a dependent variable. At first, we included all variables known by the interaction with HT: sex, age, residence, diabetes, BMI, WC and ratio $\mathrm{W} / \mathrm{H}$. After the calculations and elimination of variables without significant effect, we have identified three selected factors: diabetes with an OR $=6,6$ (CI95\% [3,52-9,05]); obesity (calculated by BMI) with an $\mathrm{OR}=1,8(\mathrm{CI} 95 \%[1,55-2,62]) ;$ and finally age with an $\mathrm{OR}=1,2$ (CI95\% [1,06-2,27]).

The relationship between HT, diabetes and obesity is well elucidated in the literature (Garcia et al. 2008; Gus et al. 2004; Chuang et al. 2006). It is known that obese subjects have higher tension values, associated with a cardiac output and a blood volume so high than the subjects with normal weight (Garcia et al. 2008). In the same context, the pancreas of the obese person secretes more insulin compared to a non obese subject to confront the insulin resistance and counteract high rate of the glycemia (Garcia et al. 2008; Lean et al. 1990; Haslam and James 2005).

This hyperinsulinemia generates many physiological modifications (Schinner et al. 2005), such the increase of the rate of adrenaline and consequently the cardiac output (Lean et al. 1990; Haslam and James 2005), and the narrowing of blood vessels which results in an increase in stiffness and an elevation of blood pressure. On the renal level, hyperinsulinemia promotes the reabsorption of $\mathrm{Na}+$ and water, which leads subsequently to an increase of blood volume and the blood pressure (Jansen et al. 2010). The positive effect of the age on HT is known, especially when it is associated with other risk factors such as diabetes and obesity (Renzaho et al. 2014).

\section{Conclusions}

This study has achieved major objectives traced for this work, we have estimated the frequency of HT in the east of Morocco (31.7\%), and we have also proved and calculated for the first time the different relationship between HT, type 2 diabetes and obesity in this region. The high frequency of HT and also diabetes and obesity in the east of Morocco require the adoption of a global, urgent and effective strategy by the ministry of health, which must involve all the organizations and interested people of the civil society.

\section{Competing interests}

The authors declare that they have no competing interests.

\section{Authors' contributions}

$\mathrm{AZ}$ is the project leader and participated in all stages of this work. NR conducted the field work, completed an internship in Belgium to perform the statistical analysis and writing the first draft of the manuscript. NB has reviewed all the statistical analysis of the study. JV framed NR during the training in Belgium and led the statistical analysis of data. $\mathrm{BH}$ is one of the organizers of medical campaigns that actively participated in the implementation of the field survey; $A B$ assisted in the selection of the sampling method and reviewing the manuscript. MA, HM, MB and AL participated in the discussion of the results and reviewing the manuscript. All authors read and approved the final manuscript.

\section{Acknowledgments}

We thank the CUD of Belgium which financed the training course made in the University Hospital Brugmann (Brussels, Belgium) within the framework of the program 3 of cooperation with the University Mohamed Premier (Oujda, Morocco). We also thank all persons and institutions which participated in this study in particular (Club 'Majd' of young diabetics), (Le syndicat des médecins de l'oriental) and the Advisor therapist delegate of Aventis laboratories at Oujda.

\section{Author details}

${ }^{1}$ Laboratoire de Physiologie et Ethnopharmacologie, Département de Biologie - Faculté des Sciences, Université Mohamed Premier, B.P. 717, Boulevard Mohamed VI, Oujda 60000, Maroc. ${ }^{2}$ Medical Microbiology Laboratory, Communicable and Infectious Diseases, Institut Scientifique de Santé Publique, Rue Engeland 642; 1180, Bruxelles, Belgique. ${ }^{3}$ Médecin endocrinologue diabétologue, Bd. Mohamed Abdou Imm. Sâada 1er étage, Oujda, Maroc. ${ }^{4}$ Laboratoire de modélisation stochastique et déterministe, Univ Mohammed I, Fac. Sciences, Oujda, Maroc.

Received: 24 July 2014 Accepted: 15 October 2014

Published: 30 October 2014

\section{References}

Alberti KGMM, Zimmet PJ, for the WHO (1998) Consultation Group. Definition and classification of diabetes mellitus and its complications. Part 1: Diagnosis and classification of diabetes mellitus provisional report of a WHO Consultation. Diabet Med 15:539-53

Aprahamian TR, Sam F (2011) Adiponectin in Cardiovascular Inflammation and Obesity. Int J Inflam 2011:8, Article ID 376909

Barrios V, Escobar C, Bertomeu V, Murga N, de Pablo C, Calderón A (2008) Sex differences in the hypertensive population with chronic ischemic heart disease. J Clin Hypertens 10(10):779-786

Berraho M, El Achhab Y, El Rhazi K, Tachfouti N, Benslimane A, Nejjari C (2009) L'hypertension artérielle chez 525 diabétiques de type 2 - étude transversale dans trois régions au Maroc. Revue d'Epidémiologie et de Santé Publique 57(S1):15

Boukli Hacène L, Meguenni K (2007) Cardiovascular risk factors in Tlemcen (Algeria). Sante 17(3):153-8

Chuang SY, Chou P, Hsu PF, Cheng HM, Tsai ST, Lin IF, Chen CH (2006) Presence and progression of abdominal obesity are predictors of future high blood pressure and hypertension. Am J Hypertens 19:788-795

Cohuet G, Struijker-Boudier H (2006) "Mechanisms of Target Organ Damage Caused by Hypertension: Therapeutic Potential". Pharmacol Ther 111(1):81-98

Da Silva AA, Do Carmo J, Dubinion J, Hall JE (2009) The role of the sympathetic nervous system in obesity-related hypertension. Curr Hypertens Rep 11(3):206-11

Fidiarivony R, Irina IA, Rondro NR, Andrianaivo R (2010) Profil épidémiologique des diabétiques hypertendus hospitalisés en médecine interne au CHU de Mahajanga Madagascar. e-Santé. Revue électronique en sciences de la santé $\mathrm{N}^{\circ} 01: 18-23$

Garcia C, Le Berre JP, Mayaudon H, Bordier L, Dupuy O, Bauduceau B (2008) Obésité abdominale, insulinorésistance et niveau de la pression artérielle. Diabetes Metab 34(n S3):H89

Godet-Thobie H, Vernay M, Noukpoape A, Salanave B, Malon A, Castetbon K, de Peretti C (2008) Niveau tensionnel moyen et prévalence de l'hypertension artérielle chez les adultes de 18 à 74 ans, ENNS 2006-2007. BEH, décembre 49-50:478-483

Grossman E, Messerli FH (1996) Diabetic and hypertensive heart disease. Ann Intern Med 125(4):304-10

Gus M, Fuchs SC, Moreira LB, Moraes RS, Wiehe M, Silva AF, Albers F, Fuchs FD (2004) Association between different measurements of obesity and the incidence of hypertension. Am J Hypertens 17(1):50-53

Hall J, Hildebrandt D, Kuo J (2001) Obesity hypertension: role of leptin and sympathetic nervous system. Am J Hypertens 14(6):103S-115S

Haslam DW, James WP (2005) Obesity. Lancet 366:1197-1209 
Hayashi T, Boyko EJ, Leonetti DL, McNeely MJ, Newell-Morris L, Kahn SE, Fujimoto WY (2004) Visceral adiposity is an independent predictor of incident hypertension in Japanese Americans. Ann Intern Med 140:992-1000

Howards J, Bower K, Wayne P (2006) Factors Influencing the Management of Hypertension in Type 2 Diabetes. Can J Diabetes 30(1):38-45

Jansen PM, Jan A, Danser H, Wilko S, Anton H, Van Den M (2010) Drug Mechanisms to Help in Managing Resistant Hypertension in Obesity. Curr Hypertens Rep 12(4):220-225

Janssen I, Katzmarzyk PT, Ross R (2004) Waist circumference and not body mass index explains obesity-related health risk. Am J Clin Nutr 79:379-384

Joffres MR, Ghadirian P, Fodor JG, Petrasovits A, Chockalingam A, Hamet P (1997) Awareness, treatment, and control of hypertension in Canada. Am J Hypertens 10:1097-102

Jordan J, Engeli S, Redon J, Sharma AM, Luft FC, Narkiewicz K, Grassi G (2007) European Society of Hypertension Working Group on Obesity. J Hypertens 25(4):897-900

Karppanen H, Mervaala E (2006) Sodium Intake and Hypertension. Prog Cardiovasc Dis 49(2):59-75

Lean ME, Powrie JK, Anderson AS, Garthwaite PH (1990) Obesity weight loss and prognosis in type 2 diabetes. Diabet Med 7:228-33

Mancia G, De Backer G, Dominiczak A, Cifkova R, Fagard R, Germano G, Grassi G, Heagerty AM, Kjeldsen SE, Laurent S, Narkiewicz K, Ruilope L, Rynkiewicz A, Schmieder RE, Struijker Boudier HA, Zanchetti A, Vahanian A, Camm J, De Caterina R, Dean V, Dickstein K, Filippatos G, Funck-Brentano C, Hellemans I, Kristensen SD, McGregor K, Sechtem U, Silber S, Tendera M, Widimsky P et al (2007) Guidelines for the management of arterial hypertension: The Task Force for the Management of Arterial Hypertension of the European Society of Hypertension (ESH) and of the European Society of Cardiology (ESC). Eur Heart J 28(12):1462-536

Maniecka-Bryla I, Szymocha M, Bryla M (2011) Overweight and obesity as risk factors in hypertension-study of the working population. Med Lav 102(6):523-38

Nejjari C, Arharbi M, Chentir M-T, Boujnah R, Kemmou O, Megdiche H, Boulahrouf F, Messoussi K, Nazek L, Bulatov V (2013) Epidemiological Trial of Hypertension in North Africa (ETHNA): an international multicentre study in Algeria, Morocco and Tunisia. J Hypertens 31(Issue 1):49-62

Ramdani N, Vanderpas J, Boutayeb A, Meziane A, Hassani B, Zoheir J, Legssyer A, Aziz M, Mekhfi H, Bnouham M, Ziyyat (2012) Diabetes and obesity in the eastern Morocco. Mediterr. J Nutr Metab 5(Issue 2):149-155

Renzaho A, Bilal P, Marks G (2014) Obesity, Type 2 Diabetes and High Blood Pressure Amongst Recently Arrived Sudanese Refugees in Queensland. Australia. J Immigr Minor Health 16(1):86-94

Rosenthal T, Alter A (2012) Occupational stress and hypertension. J Am Soc Hypertens 6(1):2-22, Epub 2011 Oct 22

Schinner S, Scherbaum WA, Bornstein SR, Barthel A (2005) Molecular mechanisms of insulin resistance. Diabet Med 22:674-82

Sowers JR (2003) Recommendations for special populations: diabetes mellitus and the metabolic syndrome. Am J Hypertens $16(11 \mathrm{Pt} 2): 41 \mathrm{~S}-45 \mathrm{~S}$

Stamler J, Vaccaro O, Neaton JD, Wentworth D (1993) For the multiple risk factor intervention trial research group : diabetes, other risk factors and 12-yr cardiovascular mortality for men screened in the multiple risk factor intervention trial. Diabetes Care 16:434-44

Tazi MA, Abir-Khalil S, Chaouki N, Cherqaoui S, Lahmouz F, Srairi JE, Mahjour J (2003) Prevalence of the main cardiovascular risk factors in Morocco: results of a national survey, 2000. J Hypertens 21(5):897-903

The National High Blood Pressure Education Program Working Group (1994) National High Blood Pressure Education Program Working Group report on hypertension in diabetes. Hypertension 23:145-158

UKPDS (1998) Intensive blood-glucose control with sulphonylureas or insulin compared with conventional treatment and risk of complications in patients with type 2 diabetes. Lancet 352:837-853

Vargas Alarcón G (2006) Physiopathogenesis of hypertension. Arch Cardiol Mex 76(Suppl 2):S157-60

WHO (1985) Multinational study of vascular disease in diabetics: Prevalence of small and large vessel disease in diabetics patients rom 14 centres. Diabetologie 28:615-640

WHO (2003) Obésité: prévention et prise en charge de l'épidémie mondiale. Rapport d'une consultation de l'OMS. OMS, Série de Rapports techniques Nº 894, Genève
WHO (2012) Statistiques sanitaires mondiales. (Classification NLM: WA 900.1) Coverage by WHO Graphics; Layout by Court Consulting, Printed in Switzerland. ISBN 9789242564440

Ziyyat A, Legssyer A, Mekhfi H, Dassouli A, Serhrouchni M, Benjelloun W (1997) "Phytotherapy of Hypertension and Diabetes in Oriental Morocco". J Ethnopharmacol 58(1):45-54

doi:10.1186/2193-1801-3-644

Cite this article as: Ziyyat et al:: Epidemiology of hypertension and its relationship with type 2 diabetes and obesity in eastern Morocco.

SpringerPlus 2014 3:644

\section{Submit your manuscript to a SpringerOpen ${ }^{\circ}$ journal and benefit from:}

- Convenient online submission

- Rigorous peer review

- Immediate publication on acceptance

- Open access: articles freely available online

- High visibility within the field

- Retaining the copyright to your article

Submit your next manuscript at $>$ springeropen.com 